\title{
CONHECIMENTO, SENTIMENTOS E RELACIONAMENTO AFETIVO DE HOMENS PORTADORES DE PAPILOMAVÍRUS HUMANO
}

\section{KNOWLEDGE, FEELINGS AND AFFECTIVE RELATIONSHIP OF MEN WITH HUMAN PAPILLOMAVIRUS}

\author{
Helder Ferreira ${ }^{1}$ \\ Mirna Chamorro Aguero ${ }^{2}$ \\ Cynthia Borges de Moura $^{3}$
}

\begin{abstract}
Resumo: Objetivou identificar o nível de conhecimento, sentimentos e a possível interferência no relacionamento afetivo de homens portadores de Papilomavirus humano (HPV). Foram entrevistados 15 homens portadores de HPV atendidos em um ambulatório de Doenças sexualmente transmissíveis. Estudo qualitativo, mediante a aplicação do método de Análise de Conteúdo, que gerou categorias e subcategorias. A grande maioria entendia que o HPV é uma verruga e que a transmissão se deu pelo contato sexual. Quanto às reações emocionais, 31,1\% relataram sentimento de medo intenso frente ao diagnóstico e 34,7\% afirmaram que passaram a usar preservativo. Concluiu-se que os participantes tinham pouco conhecimento sobre o HPV, o principal sentimento foi o medo e a mudança ocorrida em seus relacionamentos foi à aquisição do hábito de usar preservativo.
\end{abstract}

Palavras-chave: Papillomaviridae; Saúde do Homem; Emoções; Conhecimento.

\begin{abstract}
The objective was to identify the level of knowledge, feelings and possible interference in the affective relationship of men with human papillomavirus (HPV). Fifteen men with HPV who had been treated at an outpatient clinic for sexually transmitted diseases were interviewed. Qualitative study, through the application of the Content Analysis method, which generated categories and subcategories. The vast majority understood that HPV is a wart and they said that the transmission was through sexual contact. As for emotional reactions, $31.1 \%$ reported intense fear feelings about the diagnosis and $34.7 \%$ said they had no problem with the affective relationship. It was concluded that the participants had little knowledge about HPV, the main feeling was fear and the change occurred in their relationships was the acquisition of the habit of using a condom.
\end{abstract}

Keywords: Papillomaviridae; Men's Health; Emotions; Knowledg.

\section{Instrodução}

A infecção pelo Papilomavírus humano (HPV) no trato genital é a doença sexualmente transmissível (DST) de maior freqüência em todo o mundo (BURLAMAQUI et al., 2017). O vírus do HPV está associado a várias patologias que acometem crianças e adultos de ambos os sexos, tais como câncer de colo de útero, de

\footnotetext{
${ }^{1}$ Doutor em Saúde Públiva, Universidade de São Paulo (USP). Universidade Estadual do Oeste do Paraná (Unioeste), Foz do Iguaçu-PR, Brasil. E-mail: heelfer@gmail.com

${ }^{2}$ Especialista em Saúde Pública, Universidade do Norte do Paraná (UNOPAR). Universidade Estadual do Oeste do Paraná (Unioeste), Foz do Iguaçu-PR, Brasil. E-mail: mirnaaguero@ hotmail.com

${ }^{3}$ Doutora em Psicologia, Universidade de São Paulo (USP). Universidade Estadual do Oeste do Paraná (Unioeste), Foz do Iguaçu-PR, Brasil. E-mail: cynthia-moura@ hotmail.com
} 
vulva, de pênis, de anus, de boca, orofaringe e verrugas anogenitais (BRASIL, 2017; BURLAMAQUI et al., 2017).

Muito se tem estudado sobre o HPV em mulheres, no entanto, estudos da mesma natureza em homens não são tão comuns, até mesmo quando se estuda mulheres portadoras de HPV que vivem maritalmente (ARCOVERDE; WALL, 2005). Tal fato representa um problema de saúde pública, visto que, o número de câncer de pênis no Brasil, associado ao HPV, vem aumentando significativamente nas últimas décadas, estando o Brasil em segunda colocação entre os países com os maiores números desta patologia (LEITE, et al., 2015).

Conhecer a prevalência e os fatores associados aos cuidados com o homem portador de HPV se torna imprescindível para que se possam estabelecer ações de prevenção e atenção a estes indivíduos. Assim, o objetivo deste trabalho foi identificar o nível de conhecimento, sentimentos e a possível interferência no relacionamento afetivo de homens portadores de HPV.

\section{Metodologia}

Trata-se de uma pesquisa descritiva, qualitativa, mediante a aplicação do método de Análise de Conteúdo.

A pesquisa foi realizada em um município do estremo oeste do estado do Paraná, que faz divisa com o Paraguai e Argentina, no ano de 2012. Participaram da pesquisa, 15 homens com diagnóstico de HPV atendidos no ambulatório de Doenças Sexualmente Transmissíveis (DST), sendo este, o local da coleta de dados. O ambulatório é um serviço público municipal, considerado Centro de Referência que objetiva prestar assistência individual e coletiva a pacientes portadores de HPV e outras DST's.

Utilizou-se para a coleta dos dados um formulário com as seguintes perguntas: 1 . Você sabe o que é HPV?; 2. Você sabe como se transmite o HPV?; 3.Você sabe como não pegar HPV?; 4.0 que você sentiu quando soube que estava com HPV?; 5.Como ficou seu relacionamento com sua esposa/namorada após o HPV?.

A coleta dos dados ocorreu após a explicação dos objetivos da pesquisa e o aceite da gravação da entrevista e a assinatura do Termo de Consentimento Livre e Esclarecido (TCLE). A entrevista era iniciada e após o seu término a mesma era ouvida por ambos (entrevistador/entrevistado) para o parecer do entrevistado e validação. 
Foi realizada a análise dos depoimentos, no qual o primeiro passo constituiu-se da transcrição literal das fitas gravadas. A transcrição e a organização dos discursos respeitaram a ordem em que foram realizadas as entrevistas, que foram identificadas por numeros. Posteriormente foi feita a análise dos dados e sua categorização e subcategorias, através do Método de Análise de Conteúdo.

A pesquisa foi aprovada pelo Comitê de Ética da Universidade Estadual do Oeste do Paraná sob parecer 398/2010-CEP por respeitar e atender as normas da Resolução 466/2012, que envolve pesquisas com seres humanos.

\section{Resultados e Discussões}

A amostra estuda foi composta por um total de 15 homens com idade entre 15 e 30 anos, vivendo maritalmente ou namorando.

A fim de facilitar a compreensão e análise dos dados, foi criado categorias e subcategorias de acordo com as temáticas retiradas das falas dos participantes durante as entrevistas realizadas, sendo elas:

\subsection{Categoria 1: Definição de HPV}

Dentro desta categoria foi possível formar 4 subcategorias, todas relacionadas ao nível de conhecimentos dos homens entrevistados sobre a definição do HPV, como demonstra a tabela 1 .

Tabela 1: Conhecimento dos homens atendidos em um ambulatório de referência do município de Foz do Iguaçu-PR sobre a definição do HPV $(n=15)$

\begin{tabular}{lccc}
\hline Definição & n & $\%$ \\
\hline Verrugas & 7 & $\frac{46,7}{2}$ \\
Não sabe & 4 & 26,7 \\
Doença Sexualmente Transmissível & 2 & 13,3 \\
Vírus & 2 & 13,3 \\
\hline
\end{tabular}

\section{Fonte: Ambulatorio de DST's}

Podemos observar que a subcategoria Verruga, foi a mais presente no entendimento da doença entre as respostas dos homens do estudo, representando 46,7\% das unidades de análise. A infecção genital pelo HPV pode ser clínica, subclínica e latente. A forma clínica é facilmente detectada, em forma de lesão verrugosa, possível de ser evidenciada a olho nu nas regiões perianal e genitália externa que aumentam com o 
decorrer do tempo. Com isto, estes pacientes acabam atribuindo à esta característica clínica a definição da doença (BRASIL, 2013). Os homens em sua grande maioria só procuram atendimento médico ou orientação quando apresentam estes sintomas avançados que causam incômodos, antes disso, os homens são resistentes no cuidado da sua saúde, mediante a vergonha, a sentimentos de medo, e por causas comportamentais como o descuido, a impaciência e prioridades de vida (TEIXEIRA; CRUZ, 2016).

Foi possível verificar neste estudo que $26,7 \%$ das unidades de análise fazem parte da subcategoria "Não sabe", caracterizando uma parcela quantitativa considerável de homens entrevistados com ausência de conhecimento sobre a doença que portam e que estão em tratamento. Outras pesquisas mostram que o conhecimento sobre o HPV é inadequado para diversas populações (OSIS; DUART; SOUSA, 2014; PANOBIANCO et al., 2013; DAHLSTRÖM et al., 2012).

É possível visualizar que as subcategorias Doença Sexualmente Transmissível e Vírus, ambas foram representadas por $13,3 \%$ das unidades de análise. Sendo estas definições corretas, porem, incompletas, pois, o HPV é um vírus e de transmissão predominantemente sexual (ZARDO; FARAH,; MENDES, 2014).

O conhecimento dos homens portadores de HPV que participaram deste estudo, sobre a definição desta doença ao qual portavam, é ausente ou incompleto. Este fato reforça a necessidade de intervenções educativas na população para prover informação adequada sobre o HPV e sobre medidas de prevenção.

\subsection{Categoria 2: Transmissão do HPV}

Dentro desta categoria foi possível formar 4 subcategorias, todas relacionadas ao nível de conhecimentos dos homens entrevistados sobre as formas de transmissão do HPV, como demonstra a tabela 2.

Tabela 2: Conhecimento dos homens atendidos em um ambulatório de referência do município de Foz do Iguaçu/PR sobre a forma de transmissão do HPV $(n=15)$.

\begin{tabular}{lccc}
\hline Transmissão & n & \% \\
\hline Relações sexuais & 7 & 43,8 \\
Não sabe & 6 & 37,5 \\
Relações sexuais sem preservativo & 2 & 12,5 \\
Contato com Sangue & 1 & 6,2 \\
\hline
\end{tabular}

Fonte: Ambulatorio de DST's 
É possível visualizar que $43,8 \%$ das respostas dos homens com HPV correspondem à subcategoria "Relações Sexuais", isto demonstra que a maior parte dos homens possuíam uma concepção correta em relação às formas de transmissão do HPV. Ainda dentro deste contexto, $12,5 \%$ das unidades de análise estão relacionadas à subcategoria "Relação sexual sem a utilização do preservativo", o que pode sugerir um melhor entendimento na forma de transmissão do HPV.

Vale ressaltar que hábitos como sentar, usar a mesma toalha podem transmitir a doença, em se tratando desta via, também conhecida como o contato não sexual, alguns estudos afirmam que seja provável a contaminação, embora não se saiba por quanto tempo o vírus resista fora do organismo, considera-se que a transmissão por "fômites" (toalhas, roupas íntimas e de cama) seja viável por um curto período de tempo (RYNDOCK; MEYERS, 2014).

Podemos observar que 37,5\% das respostas desta categoria estão relacionadas à subcategoria "Não sabe", isto demonstra que uma parte considerável dos homens entrevistados não possuem concepção sobre as formas de transmissão da doença ao qual são portadores. É possível visualizar um entendimento errôneo em relação às formas de transmissão do HPV, como o "Contato com sangue", que corresponde à 6,2\% das unidades de análise.

A carência de informações adequadas a respeito do HPV pode favorecer o desenvolvimento de concepções errôneas que, por sua vez, podem interferir de forma negativa no comportamento dos portadores do HPV, bem como das pessoas que fazem parte de seu contexto sócio-familiar. Os entendimentos errôneos encontram-se, na maioria das vezes, fundamentados em elementos culturais, tais como crenças, mitos e tabus, que têm um grande significado para o indivíduo. Os valores culturais sem correspondência com a realidade podem representar uma grande barreira para os profissionais que atuam na promoção e reabilitação da saúde e na prevenção de doenças (GUERREIRO; AYRES; HEARST, 2002).

Faz-se necessário que as políticas públicas para a saúde do homem atuem na cultura masculina com a finalidade de promover saúde e romper com o ciclo da infecção desta DST, pois a transmissão do HPV para o trato genital ocorre por meio do contato sexual e é de extrema importância a educação da população quanto ao modo de transmissão. A educação compreende a prevenção e a detecção precoce da doença, sendo importante a realização de campanhas de conscientização, enfatizando que o homem é o 
principal transmissor do vírus para as mulheres, devendo ser alvo da educação preventiva (BURLAMAQUI et al., 2017).

\subsection{Categoria 3: Prevenção do HPV}

Dentro desta categoria foi possível formar 3 subcategorias, todas relacionadas ao nível de conhecimentos dos homens entrevistados sobre as formas de prevenção do HPV, como demonstra a tabela 3 .

Tabela 3: Conhecimento dos homens atendidos em um ambulatório de referência do município de Foz do

\begin{tabular}{lcl}
\multicolumn{1}{c}{ Iguaçu/PR sobre a forma de prevenção do HPV $(\mathrm{n}=15)$} & \\
\hline Prevenção & $\mathbf{n}$ & $\%$ \\
\hline Uso de preservativo & 9 & 56,3 \\
Não sabe & 6 & 37,5 \\
Abster-se de sexo & 1 & 6,2 \\
\hline
\end{tabular}

Fonte: Ambulatorio de DST's

Este estudo demonstra que 56,3\% das unidades de análise correspondem à subcategoria "Uso de preservativo", o que indica que grande parte dos homens entrevistados possuía conhecimento adequado sobre os meios de prevenção do HPV. O preservativo é o método mais efetivo para evitar a transmissão de DSTs, no entanto, embora seu uso esteja aumentando, sobretudo nos últimos anos, está muito longe de atingir níveis satisfatórios (NASCIMENTO; CAVALCANTI; ALCHIERI, 2017). O preservativo masculino garante apenas proteção de contato, ou seja, protege áreas que permanecem em contato com o preservativo, permitindo que outras regiões sejam contaminadas. Com isto, seu uso pode reduzir, mas não elimina, o risco de transmissão do HPV. O preservativo feminino, por sua vez, garante maior proteção, por apresentar uma maior superfície (BELÉM et al., 2015).

Podemos observar nesta categoria que $37,5 \%$ das unidades de análise correspondem à subcategoria "Não sabe", o que caracteriza um baixo nível de conhecimento sobre a prevenção do HPV em grande parte dos homens entrevistados. Enquanto 6,2\% das unidades de análise correspondem à subcategoria "Abster-se de sexo". O desconhecimento da doença e de suas formas de prevenção induzem os homens infectados com o HPV a adotarem posturas e condutas inadequadas com relação à prevenção, pois os mesmos passam a ter conhecimento sobre a doença após a infecção por HPV e, mesmo assim, ainda apresentam dúvidas (DA FONTE et al., 2017). 
O homem é educado e estimulado durante toda a sua vida para ser forte e provedor e isto o faz sentir-se invulnerável, colocando-os numa posição de vulnerabilidade física e psíquica já que não podem admitir que são frágeis ou que podem adoecer. Conseqüentemente recorrem menos aos tratamentos médicos e morrem mais cedo do que as mulheres. Esta visão em relação ao sexo masculino acaba por ter reflexos nos serviços de saúde, onde as políticas públicas neste setor têm sido executadas de maneira insuficiente (DA FONTE et al., 2017; TEIXEIRA; CRUZ, 2016).

A cultura da sociedade sobre o papel do homem como um ser superior, cria um grande impedimento na busca dos homens portadores de problemas de saúde. A existência do pudor na exposição do corpo perante o profissional de saúde constitui motivo para a não busca de cuidados de saúde, além do medo de se descobrir com alguma doença. Os serviços públicos são percebidos como espaço voltado ao público feminino, provocando no homem uma sensação de constrangimento. A procura do homem pelo serviço de saúde, só acontece quando não existem mais alternativas a tomar, pois a busca dos serviços de saúde de forma preventiva pode ser associada à fraqueza masculina. As farmácias e drogarias têm um papel importante neste processo, pois o homem acaba buscando em seus balcões, através de conselhos não profissionais, orientações e solução para seu problema de saúde (ARCOVERDE; WALL, 2005; TEIXEIRA; CRUZ, 2016; SCUSSEL; MACHADO, 2017).

\subsection{Categoria 4: Reações emocionais}

Dentro desta categoria foi possível formar 8 subcategorias, todas relacionadas às reações emocionais vivenciadas após o diagnóstico de HPV nos homens entrevistados, como demonstra a tabela 4 .

Tabela 4: Reações emocionais vivenciadas após o diagnóstico de HPV nos homens atendidos em um ambulatório de referência do município de Foz do Iguaçu/PR $(\mathrm{n}=15)$

\begin{tabular}{lcc}
\hline Reações Emocionais & $\mathbf{n}$ & \% \\
\hline Medo & 9 & 31,1 \\
Normal/Tranqüilo & 4 & 13,8 \\
Preocupado/Assustado & 4 & 13,8 \\
Desesperado/Em choque & 3 & 10,3 \\
Arrependimento e Culpa & 3 & 10,3 \\
Raiva & 2 & 6,9 \\
Nojo de si próprio & 2 & 6,9 \\
Vergonha/Constrangimento & 2 & 6,9 \\
\hline
\end{tabular}

Fonte: Ambulatorio de DST's 
Ao tomar conhecimento do diagnóstico de uma doença, o homem se depara com um conflito interior, no sentido genérico, uma mudança, uma alteração, uma passagem de determinada situação para outra desconhecida, por isso, passível de gerar ansiedade. O impacto produzido por uma doença qualquer no sexo masculino é extremamente complexo (DÁZIO et al., 2009).

Um estudo realizado por Gomes e colaboradores (2011), mostrou que os homens procuram os serviços de saúde para tratamento, apenas quando se apresentam sintomáticos. Para Separavich e Canesqui (2013), é muito difícil para o homem ocupar o papel de paciente e com freqüência ele nega a possibilidade da doença, procurando assistência em última instância. Observa-se que em se tratando de infecção do HPV, essa relação não é diferente.

Neste estudo o "Medo" corresponde à 31,1\% das unidades de análise, caracterizando a maior parte das respostas dos homens entrevistados. O medo por não conhecer a doença e sua evolução clínica, de perda do órgão genital, do preconceito e de prejudicar outras pessoas são os mais citados nas falas dos homens entrevistados. Enquanto a subcategoria "Preocupado/Assustado" corresponde à 13,8\% das unidades de análise.

A grande preocupação dos portadores de HPV são as consequiências que ocorrerão na vida social e sexual. O homem em geral é muito dependente de sua sexualidade e considera o pênis seu órgão principal. O portador de HPV tem sua vida sexual prejudicada e com isto, surge a insegurança em todos os aspectos de sua vida (SANTOS; MAIORAL, M.F; HAAS 2009).

O medo é um sentimento característico em homens infectados pelo HPV, pela incerteza da cura, recidiva e do prognóstico da doença. É sob o aspecto da incerteza que os pacientes infectados vivem. Esse sentimento amplia sua dimensão quando o imaginário destaca a influência da doença na sua vida profissional, o medo de perder o emprego por causa das consultas semanais, o receio de prejudicar as conquistas amorosas por ter que expor o problema para a parceira, escapar do assédio ao ato sexual, como também medo do próprio ato em si, de transmitir essa doença para alguém, tudo isso representa a sensibilidade aguçada traduzida pelo HPV (QUEIROZ; BRAGA; XIMENEZ, 2006).

Podemos observar que nesta categoria, a subcategoria "Normal/Tranqüilo" também corresponde à 13,8\% das unidades de análise, caracterizando homens que não manifestaram nenhum problema frente ao diagnóstico da doença. Entretanto, isso pode ser atribuído a uma forma de desconhecimento da doença ou à não assimilação adequada 
do valor atribuído a esse vírus no momento do diagnóstico, o portador de HPV, do gênero masculino tem muita dificuldade de demonstrar seu lado interior no tocante aos sentimentos, podendo também ser considerado um mecanismo de defesa dos sujeitos para não expor a sensibilidade masculina e os sofrimentos frente à infecção por HPV (TEIXEIRA; CRUZ, 2006; SANTOS et al., 2011).

Em relação às subcategorias "Desesperado/Em choque" e "Arrependimento e Culpa”, ambas correspondem à 10,3\% das unidades de análise respectivamente.

Os sentimentos de arrependimento, culpa e desespero são evidenciados nos homens infectados pelo vírus, visto que o HPV, por ser sexualmente transmissível, pode levantar questionamentos como infidelidade em conduta sexual. Este sofrimento é ressaltado como forma de angústia, por descobrir-se um portador de uma moléstia crônica contagiosa, e também por ser responsável pela mudança na qualidade do seu relacionamento afetivo e sexual. Saber que foi vencido pelo orgulho, pela autoconfiança e até mesmo pelo ego (QUEIROZ; BRAGA; XIMENEZ, 2006; SILVEIRA et al., 2012). Considerando o homem, um importante meio propagador na cadeia de transmissão desta DST, há estudos que relatam que os mesmos apresentam medo e culpa em saber que foram eles os transmissores de alguma doença à parceira (GUERREIRO; AYRES; HEARST, 2002; MARQUES; GOMES; NASCIMENTO, 2012).

As reações emocionais relacionadas à "Raiva", correspondem à 6,9\% das unidades de análise. Este sentimento é evidenciado em questionamentos em relação à curiosidade para identificar o parceiro que foi a fonte de contaminação. Como não se conhece o período de incubação, é possível que o vírus permaneça em estado latente, sem se manifestar por um longo período, assim, na prática clínica, é praticamente impossível estabelecer um tempo provável para contaminação. A resposta poderia ser buscada em outros dados, como a presença de um único parceiro ou um contato sexual suspeito (ROSENBLATT et al., 2004; OYEDIRAN et al., 2010).

As subcategorias "Nojo de si próprio" e "Vergonha/Constrangimento" também correspondem à 6,9\% das unidades de análise respectivamente. Isto pode ser atribuído ao fato de que as lesões comprometem a aparência do órgão genital, gerando conflitos em relação à vida sexual destes pacientes.

A identificação do estado emocional do homem quando recebe a confirmação de positividade da DST, pode agregar valor ao trabalho dos profissionais de saúde, por levar à otimização da qualidade de assistência a esses pacientes (BOCHEMBUZIO; MENEGHIN, 2000; PEQUENO; MACEDO; MIRANDA, 2013). 
Uma das especificidades do trabalho dos profissionais de saúde que trabalham em centros de aconselhamento para as DST's, é lidar com diferentes questões emocionais do paciente. Por isto, deve lançar mão de instrumentos básicos da relação de ajuda tais como o diálogo e sentimentos de humanidade capazes de permitir ao cliente desfrutar do bem estar, e ter razões para atingir a cura, com abordagem a uma assistência biopsicossocial individualizada (PEQUENO et al., 2013).

\subsection{Categoria 5: Repercussão no relacionamento afetivo}

Dentro desta categoria foi possível formar 4 subcategorias, todas relacionadas às repercussões no relacionamento afetivo após a infecção do HPV nos homens entrevistados, como demonstra a tabela 5.

Tabela 5: Repercussões no relacionamento afetivo após a infecção do HPV nos homens atendidos em um ambulatório de referência do município de Foz do Iguaçu/PR $(\mathrm{n}=15)$

\begin{tabular}{lcc}
\hline Relacionamento Afetivo & $\mathbf{n}$ & \% \\
\hline Passaram a usar preservativo & 9 & 39,1 \\
Sem alteração no relacionamento & 8 & 34,7 \\
Piora no relacionamento & 3 & 13,1 \\
Não possui parceira & 3 & 13,1 \\
\hline
\end{tabular}

Fonte: Ambulatorio de DST's

O indivíduo, ao sentir-se portador de uma doença sexualmente transmissível como o HPV, que é visível em seu genital, com pouca ou nenhuma possibilidade natural de reversão e carregada de preconceitos sociais se vê estigmatizado por um padrão de sociedade políticamente correta (SEIDIL; RIBEIRO; GALINKIN, 2010). Este fato começa a suscitar inúmeras interpretações em diversos campos do saber, haja vista que a atitude dos homens está ligada às representações simbólicas de masculinidade historicamente construídas, e que são mutáveis e relacionais. Fatores biológicos, psíquicos, sociais, entre outros, podem interferir no desenvolvimento e na expressão da sexualidade dos indivíduos do sexo masculino, refletindo em seus relacionamentos conjugais (CORREA; SOUZA, 2016).

Aqueles que contraem o HPV sofrem, entre outras pressões, a vergonha de serem promíscuos, o medo de serem rejeitados por seu homem ou por sua mulher, a tristeza de serem considerados indignos pelas famílias e amigos, sofrem o temor do nojo provocado 
naqueles com quem vão lidar, enfim, sofrem do medo da sua morte afetiva e social (ALVES, 2004).

Neste estudo, 39,1\% das unidades de análise correspondem à subcategoria "Passaram a usar preservativo", caracterizando a maior parte dos homens entrevistados. Enquanto 34,7\% das unidades de análise correspondem à subcategoria "Sem alteração no relacionamento", sendo esta, uma parcela quantitativamente significativa, evidenciada pelo fato das parceiras destes homens infectados aceitarem bem a doença, e contribuindo com o acompanhamento nas consultas médicas e de enfermagem e incentivo e apoio ao tratamento.

A subcategoria "Piora no relacionamento", corresponde à 13,1\% das unidades de análise, evidenciada pelos conflitos masculinos em relação à sexualidade e aparência do órgão genital acometido.

Podemos observar que em relação à subcategoria "Não possui parceira", esta também corresponde à 13,1\% das unidades de análise, porém, vale ressaltar, que esta parcela quantitativa caracteriza homens sem parceira fixa, mas que possuem vida sexual ativa.

A infecção pelo HPV deve ser abordada e assistida como um problema do casal, sendo importante propiciar tratamento e orientações adequados ao homem e, assim, prevenir seqüelas, entre as quais, o câncer de pênis (BRASIL, 2017). Mesmo quando se trata do homem que é o parceiro sexual da mulher infectada e estudada, pouco se fala sobre ele. Esse fato acontece por razões sociais, culturais e históricas, e representa um problema de saúde pública, pois o HPV é um vírus que freqüentemente é transmitido por via sexual, ou seja, enquanto não se tratar os dois grupos (masculino e feminino) com o mesmo afinco, permanece a grande dificuldade de diminuir potencialmente os índices epidemiológicos referentes à infecção pelo HPV (ARCOVERDE; WALL, 2005).

\section{Considerações finais}

Em relação ao nível de conhecimento dos homens entrevistados, uma parcela significativa apresentou carência de informações adequadas a respeito da definição, prevenção e transmissão do HPV.

No que se refere às reações emocionais, deu-se a formação de diversas subcategorias devido à variedade de manifestações encontradas, sendo elas: Medo, Preocupado/Assustado, Desesperado/Em choque; Arrependimento e Culpa; Raiva; Nojo 
de si próprio e Vergonha/Constrangimento. $\mathrm{O}$ medo foi o sentimento de maior prevalência entre os homens entrevistados, sendo um sentimento característico em homens infectados pelo HPV, pela incerteza da cura, recidiva e do prognóstico da doença.

Alguns homens relataram ainda sentimentos de tranqüilidade frente à infecção, o que pode ser atribuído à falta de conhecimento da doença no momento do diagnóstico.

As ações de saúde voltadas a saúde do homem necessitam ultrapassar os modelos tradicionais de cuidado, deve-se estimular ações de promoção e prevenção à saúde por meio da educação em saúde, incluindo neste contexto ações de informação, acolhimento, e cuidado frente às necessidades específicas de cada homem. Vale ressaltar, que todo o indivíduo possui o direito à informação, à assistência em saúde e a um serviço que seja capaz de suprir suas necessidades e ainda, profissionais qualificados que realizem suas atividades com qualidade.

\section{Referências}

ALVES M. D. S. Papilomavírus humano e mal-estar: representações sociais de homens e mulheres. 2004. Dissertação (Mestrado em Enfermagem). Universidade Federal do Ceará. Fortaleza. 2004.

ARCOVERDE, M.A.M.; WALL, M.L. Assistência “prestada ao ser" masculino portador do HPV: contribuições de enfermagem. DST - J brasileiro Doenças Sex Transm., Rio de Janeiro, v.17, n.2, p: 133-7. 2005.

BELÉM, J.M. et al. Autonomia sexual feminina: o preservativo feminino nas práticas eróticas. Rev.Saúde.Com., Salvador, v.11, n.3, p. 252-265, agosto. 2015.

BOCHEMBUZIO, L; MENEGHIN, P. Humanização na assistência de enfermagem ao portador do HIV: Entendendo os sentimentos do paciente ao receber o diagnóstico. Revista O Mundo da Saúde, São Paulo, v. 24, n,24, p.291-297, agosto. 2000.

BRASIL. Ministério da Saúde. Cobertura da vacinação contra HPV pelo SUS é ampliada. Disponível em: http://www.brasil.gov.br. Acesso em: 17 jun. 2017.

BRASIL. Secretaria de Vigilância em Saúde. Guia prático sobre HPV: guia de perguntas e respostas para profissionais de saúde. Brasília; 2013.

BURLAMAQUI, J.C.F. et al. Human Papillomavirus and students in Brazil: an assessment of knowledge of a common infection - preliminary report. Braz J Otorhinolaryngol, São Paulo, v.83, n.2, p.120-125, abril. 2017.

CORREA, R.; SOUZA, A.P.V. Expressões da sexualidade: estudo a partir da construção da masculinidade em estudantes do ensino médio. Revista Ibero-Americana de Estudos em Educação, Araraguara, v.10, n. esp, p. 1545-1559, mês (se houver). 2016. Disponivel em: file://C:/Users/Admin/Downloads/8336-22126-1-SM.pdf. Acesso em: 22 ago. 2017. 
DA FONTE, V.R. F. et al. Fatores associados ao uso do preservativo entre jovens homens que fazem sexo com homens. Enfermeria Global, Murcia, v.16, n.2, p. 65-79, abril. 2017.

DAHLSTRÖM, L.A. et al. Awareness and knowledge of human papillomavirus in the Swedish adult population. J Adolesc Health, Rio de Janeiro, v. 50, n.2, p. 204-206, fevereiro, 2012. DOI:10.1016/j.jadohealth.2011.05.009

DÁZIO, E. M. R. et al. Os sentidos de ser homem com estoma intestinal por câncer colorretal: uma abordagem na antropologia das masculinidades. Rev Latino-am Enfermagem, Ribeirão Preto, v.17. n.5, p. 0108, set/out. 2009.

GOMES, R. et al. Os homens não vêm! Ausência e/ou invisibilidade masculina na atenção primária. Ciência \& Saúde Coletiva, Rio de Janeiro, v.16(Supl. 1), p. 983-992, 2011.

GUERREIRO, I; AYRES, J. R. C. M; HEARST, N. Masculinidade e vulnerabilidade ao HIV de homens heterossexuais. Revista de Saúde Pública, São Paulo, v. 36, n.4, p. 50-60, 2002.

LEITE, A.H.P. et al. Hpv como fator de risco para o câncer peniano. Revista Brasileira de Educação e Saúde, Pombal, v.5, n.3, p.1-6, jul/set, 2015.

MARQUES, J.J.S.; GOMES, R.; NASCIMENTO, E.P. Masculinidade hegemônica, vulnerabilidade e prevenção ao HIV/AIDS. Ciência \& Saúde Coletiva, Rio de Janeiro, v.17, n.2, p. 511-520, fevereiro, 2012.

NASCIMENTO, E.G.C.; CAVALCANTI, M.A.C.; ALCHIERI, J.C. Adesão ao uso da camisinha: a realidade comportamental no interior do nordeste do brasil. Revista de Salud Pública, Bogota, v. 19, n. 1, p. 39-44, ene./feb. 2017. Disponivel em: http://www.redalyc.org/pdf/422/42250687007.pdf. Acesso em: 22 de ago. 2017.

OSIS, M.J.D.; DUARTE, G.A.; SOUSA, M.H. Conhecimento e atitude de usuários do SUS sobre o HPV e as vacinas disponíveis no Brasil. Rev Sau Publ., São Paulo, v.48, n.1, p.123-33, 2014.

OYEDIRAN, K. et al. Prevalence of and factors associated with extramarital sex among Nigerian men. Am J Mens Health, Rockville, v.4, n.2, p.124-34, junho, 2010.

PANOBIANCO, M.S. et al. O conhecimento sobre o hpv entre adolescentes estudantes de graduação em enfermagem. Texto Contexto Enferm., Florianópolis. v.22, n.1, p. 201-207, 2013.

PEQUENO, C.S.; MACEDO, S.M.; MIRANDA, K.C. Aconselhamento em HIV/AIDS: pressupostos teóricos para uma prática clínica fundamentada. Rev. bras. enferm., Brasilia, v.66, n.3, p. 437-41, mai/jun. 2013.

QUEIROZ, D. T.; BRAGA, V. A. B; XIMENEZ, L. B. Homens Portadores do Papilomavírus Humano: reações emocionais na confirmação do diagnóstico. Revista de enfermagem. UERJ, Rio de Janeiro, v.14, n.3, p.405-411, jul/set. 2006.

RYNDOCK, E.J.; MEYERS, C. A risk for non-sexual transmission of human papillomavirus? Expert Rev Anti Infect Ther., Rockville, v.12, n.10, p. 1165-70, outubro. 2014.

SANTOS, C. et al. A Enfermagem na assistência à saúde e prevenção do HPV no homem. Rev. de Pesq.: cuidado é fundamental online, Rio de Janeiro, v.1, n.2, p. 372-383, set/out.2009. 
SANTOS, I.M.; MAIORAL, M.F.; HAAS, P. Infecção por HPV em homens: Importância na transmissão, tratamento e prevenção do virus. Estud Biol., Florianopolis, v.32, n.33, p.111-18, novembro. 2011.

SCUSSEL, M.R.R.; MACHADO, D. M. Política nacional de assistência integral à saúde do homem: uma revisão integrative. REFACS, Uberaba, v.5, n.2, p.235-244. 2017.

SEIDIL, E.M.F.; RIBEIRO, T.R.A.; GALINKIN, A.L. Opiniões de jovens universitários sobre pessoas com HIV/AIDS: um estudo exploratório sobre preconceito. Psico-USF, Itatiba, v. 15, n. 1, p. 103-112, abril. 2010.

SEPARAVICH, M.A.; CANESQUI, A.M. Saúde do homem e masculinidades na Política Nacional de Atenção Integral à Saúde do Homem: uma revisão bibliográfica. Saúde e sociedade, São Paulo, v.22, n.2, p. 415-28, abr/jun. 2013.

SILVEIRA, L.K.C.B. et al. Condiloma acuminado: qual o reflexo desta DST em adolescentes do sexo masculino? Adolescencia e Saúde, Rio de Janeiro, v.9, n.3, p. 72-75.jul/set. 2012.

TEIXEIRA, D.B.S.; CRUZ, S.P.L. Atenção à saúde do homem: análise da sua resistência na procura dos serviços de saúde. Revista Cubana de Enfermería, Havana, v.32, n.4, p. 01-09, setembro. 2016.

ZARDO, G.P.; FARAH, F.P.; MENDES, F.G. Vacina como agente de imunização contra o HPV. Ciência \& Saúde Coletiva, Rio de Janeiro, v.19, n.9, p. 3799-3808. 2014.

Recebido em: 07 de março de 2018.

Aceito em: 24 de agosto de 2020. 